\title{
Anti Helminthis and Molluscicidal Activity of Momordica dioica against Pheretima posthumous and Indoplanorbis exustus
}

\author{
Freny Jacob*
}

Assistant Professor, Dept. of Zoology, Vimala College (Autonomous) Thrissur-680 009, India

*Corresponding author

\section{A B S T R A C T}

\section{Keywords \\ Anti Helminthis, Molluscicidal, Momordica dioica, Pheretima posthumous, Indoplanorbis exustus.}

Article Info

Accepted:

26 June 2018

Available Online:

10 July 2018
The present study was intended to delineate the Anti Helminthis and Molluscicidal activity of Momordica dioica fruit extract. The crude extract was obtained by the employment of Soxhlet extraction method. The extract was used to screen the antagonistic activity in vitro by taking Pheretima posthumous and Indoplanorbis exustus as the study subjects. The results obtained proved the capability of extract to downregulate the biological activities of subjects. Mortality was induced by varying concentrations $(100-1000 \mathrm{ppm} / \mathrm{ml})$. Interestingly the antagonistic activity was in direct proportional with the extract administrated. The analysis of phyto-constituents revealed that the extract is composed of polyphenols, Saponins, Flavonoids etc. Therefore, it is assumed that the biological activities are complimented by the phytocomponents. The results obtained from the current studies can be further exploited in the field nutraceuticals.

\section{Introduction}

Despite of several biological advantages of Helminthis and Molluscans it is also known for its diversified infection and vector abilities (Rabiu and Subhasish, 2011). Therefore, it is essential to develop efficient control agents against them. Trematodes, the causal agents of schistosomiasis and fascioliasis are important parasites of economic and public health implications in. Schistosomiasis affects over 240 million people worldwide, with up to 700 million individuals living at risk of infection (Kumarasingha et al., 2016). The disease caused up to 250,000 deaths per year in the last decade.

Similarly, Helminthis infection causes huge revenue in agro farming. There have been several synthetic chemical compounds and nanoparticles proven their anti Helminthis and Molluscicidal activities. However, it is also observed that these compounds are mostly toxic to the environment. In this juncture it is essential to develop suitable ethnobotanical agents against this threat (Rajeswari, 2014). Momordica dioica Roxb. is a perennial, dioecious climber included in Cucurbitaceae 
family. Momordica genus contains about 80 species. According to the latest revision of Indian Momordica, there are six well identified species of which four are dioecious and two are monoecious (Bawara et al., 2010). Although this genus is originated fromIndo Malayan region, it is now found to grow in India, Bangladesh, Srilanka, Myanmar, China, Japan, South East Asia, Polynesia, Tropical Africa, and South America (Pusuloori et al., 2017)

Its cultivation up to an altitude of 1500 meters in Assam and Garo hills of Meghalaya is reported. It is commonly known as spine gourd, teasel gourd or small bitter gourd worldwide whereas in Bangladesh it is known as kakrol and in India as kankro, kartoli, kantoli, kantola, kantroli, ban karola, or jangleekarela. Kakrol is about 5-7 meters in length, a popular summer vegetable of which its fruit, young twigs and leaves are used as vegetable (Ali et al., 1991).

It is evident that the plant possess diuretic, laxative, hepatoprotective, antivenomous, antihypertensive, anti-inflammatory, antiasthmatic, antipyretic, antileprosy, antidiabetic, and antidepressant properties (Jeyadevi et al., 2012). In this study I am delineating the Molluscicidal Activity and Anthelmintic activity of Momordica dioica.

\section{Materials and Methods}

\section{Plant collection and extracts preparation}

The fruit of Momordica dioica were collected from Botanical garden of St. Mary's College, Thrissur and the identity of plant was confirmed with the help of Dr. Sr. Meena K Cheruvathur, Assistant professor, Department of Botany, St. Mary's College, Thrissur, Kerala. The dried fruits were ground to a course powder and $50 \mathrm{~g}$ of the powdered plant materials is subjected to extraction by using Soxhlet apparatus using 95\% ethanol as the solvent. The filtrate is collected after 72 hours. It is twice filtered using Whatman no. 1 filter paper and extracts were concentrated by evaporation at room temperature. The dried residue is kept in refrigerator for further studies (Cheruvathur et al., 2015).

\section{Collection of study subjects}

Pheretima posthumous were collected from vermicomposting unit of St. Mary's College, Thrissur, Kerala and washed with normal saline to remove all fecal matter. Healthy adult Indoplanorbis exustus were collected from in and around Thrissur which was brought to Laboratory. The identity of collected organisms was confirmed by the help of Dr. Dalie Domnic, Head of the department, Department of Zoology, St. Mary's College, Thrissur, Kerala. Study subjects were acclimatized in aquaria for a minimum period of four days in holding tanks containing aerated, de-chlorinated tap water and washed sand (Williams et al., 2014).

\section{Screening of anthelmintic activity}

Test samples of plant extract was prepared at the concentrations $100-1000 \mathrm{ppm} / \mathrm{ml}$ in 10 $\mathrm{ml}$ of distilled water and five worms of approximately equal size (same type), about $0.32 \mathrm{~g}$ weight were placed in each petridish containing $10 \mathrm{ml}$ of above test solution of extracts.

All the test solutions were prepared freshly before starting the experiments. Observations were made for the time taken for paralysis was noted when no movement of any sort could be observed except when the worms were shaken vigorously. Time for death of treating worms were recorded after ascertaining that worms neither moved when shaken vigorously nor when dipped in warm water. Standard drug Albendazole is taken as control for comparison (Murugamani et al., 2012) 


\section{Screening of Molluscicidal activity}

Evaluation of molluscicidal activity of Momordica dioica against snails was investigated as recommended by the World Health Organization. The solution was prepared by adding varying concentration $(100-1000 \mathrm{ppm} / \mathrm{ml})$ of plant extract in distilled water. The snails were exposed in groups of five for 24 to 48 hours to $10 \mathrm{ml}$ of each concentration of ethanolic fruit extract of Momordica dioica. Control organisms were similarly immersed in dechlorinated water. Snail mortality was identified by the contraction of the body within the shell; no response to a needle probe was taken as evidence of death (Omobhude et al., 2017).

\section{Phytochemical analysis of plant extract}

Phytochemical screening was carried out to assess the qualitative chemical composition of crude ethanolic extracts of Momordica dioica. Standard screening tests using conventional protocol, procedure, and reagents were conducted using standard procedures to identify the constituents as described previously (Talukdar and Hossain, 2014).

\section{Results and Discussion}

\section{Effect of plant extract in causing death and paralysis in Pheretima posthumous}

Ethanolic fruit extract of Momordica dioica possess dose dependent anthelmintic. At higher concentrations, it produces paralytic effect much earlier and the time to death was shorten. At higher doses, the plant extract induces $100 \%$ mortality (Figure 1). It was observed that time required for inducing paralysis and causing death is in directly proportional that with the concentration of extract administrated. Time taken for inducing paralysis was only 20 minutes when the concentration was $1000 \mathrm{ppm} / \mathrm{ml}$ whereas the time of survival was prolonged to 90 minutes in lower concentration of antagonist.

A similar kind of activity was reported in aqueous leaf extract of Annona muricata L. (Annonaceae) against Haemonchus contortus from sheep(Ferreira et al., 2013). Similarly plant extracts from Brazilian savanna also possessed Anthelmintic activity(Oliveira et al., 2017). Generally, Albendazole eliminate worm chiefly by inducing flaccid paralysis interestingly plant extract also showed same clinical symptoms therefore we assume that the mechanism of plant extract is similar to that of Albendazole (Haque et al., 1993).

Effect of plant extract in causing death in Indoplanorbis exustus

The toxic effect of active plant extracts was evident in treated snails with ethanolic fruit extract of Momordica dioica. There was a visible swelling in the cephalopodal mass. High doses of active plant extract caused the cephalopodal mass of each snail to become severely swollen, turgid and failing to mechanical stimulus with blunt needle. Mucous secreation was observed over most of the foot. Hundred percentage mortality is observed in all treated concentrations (Figure 2). Similarly Solanum Species showed Molluscicidal activity against Biomphalaria alexandrina (El-Sherbini et al., 2009) as well as (Abdel-Haleem, 2013) these observations suggests that the phytoconstituents of plants constitute its activity and it is not depending upon its trait.

\section{Phytochemical analysis of plant extract}

Phytochemical screening of ethanolic fruit extract of Momordica dioica showed the presence of alkaloids, coumarins, terpenoids, cardioglycosides, flavonoids, saponins, quinine and phenols as major chemical constituents. 
Among these, poly phenols, flavonoids are said to have anthelmintic activity (Nayak et al., 2012). Therefore, it is assumed that the activity is contributed by the presence of the polyphenols and flavonoids. Similarly saponins show Molluscicidal activity and the presence of saponins might have contributed the activity in the current study (Lemmich et al., 1995).

Fig.1 Anthelmintic activity of extract in varying concentration

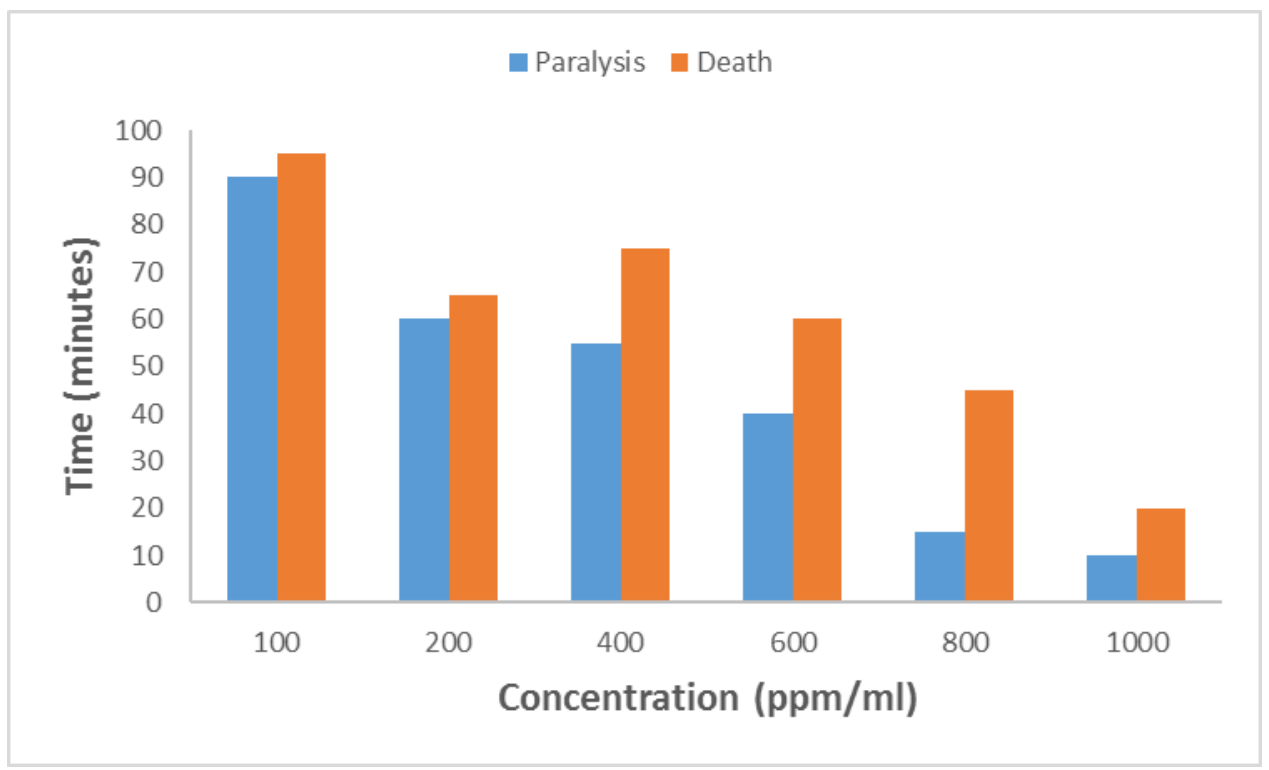

Fig.2 Molluscicidal activity of extract in varying concentration

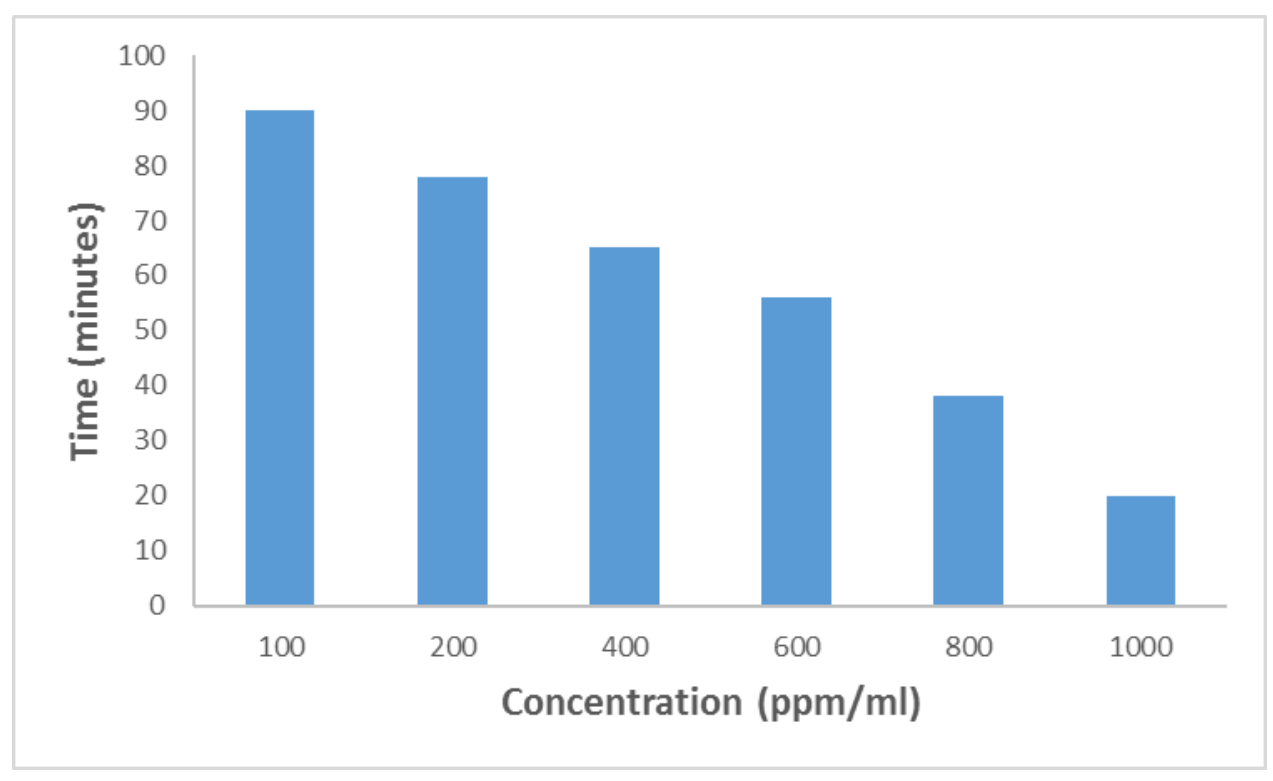


From the results, it is evident that ethanolic fruit extract of Momordica dioica possess both anthelmintic and Molluscicidal properties in a dose dependent way. $M$. dioica extract kills the worm even in low concentrations within short duration of time compared to standard drug Albendazole. It justifies the claims of its potential anthelmintic and Molluscicidal activity. It can be also exploited as a neutrasuitical agent in our body as the frequent inclusion of this vegetable in our food, eliminate intestinal parasitic worms and purifies our blood by free radical scavenging activities.

\section{Acknowledgement}

I would like to acknowledge Dr. Sr. Meena K Cheruvathur, Department of Botany; Dr. Dalie Dominic, Department of Zoology, St. Mary's College, Thrissur, Kerala and Dr. S. Vijayanand, Assistant Professor, Department of Biotechnology, Thiruvalluvar University, $\mathrm{TN}$ for their helps throughout the research.

\section{References}

Abdel-Haleem, A.A., 2013. Molluscicidal impacts of some Egyptian plant extracts on protein and DNA-contents of two snail-vectors of schistosomiasis, using electrophoresis. J. Basic Appl. Zool. 66, 34-40. https://doi.org/https://doi.org/10.1016/j jobaz.2013.01.002

Ali, M., Okubo, H., Fujii, T., Fujieda, K., 1991. Techniques for propagation and breeding of kakrol (Momordica dioica Roxb.). Sci. Hortic. (Amsterdam). 47, 335-343. https://doi.org/https://doi. org/10.1016/0304-4238(91)90017-S

Bawara, B., Dixit, M., Chauhan, N.S., Dixit, V.K., Saraf, D.K., 2010. Phytopharmacology of Momordica dioica Roxb. ex. Willd: A review. Int. J. Phytomedicine 2, 1-9. https://doi.org/10.5138/ijpm.2010.097 5.0185 .02001

Cheruvathur, M.K., Jose, B., Dennis, T., 2015. Rhinacanthin production from hairy root cultures of Rhinacanthus nasutus (L.) Kurz. Vitr. Cell. Dev. Biol. 51, 420-427.

El-Sherbini, G.T., Zayed, R.A., El-Sherbini, E.T., 2009. Molluscicidal Activity of Some Solanum Species Extracts against the Snail Biomphalaria alexandrina. J. Parasitol. Res. 2009, $1-5$.

https://doi.org/10.1155/2009/474360

Ferreira, L.E., Castro, P.M.N., Chagas, A.C.S., França, S.C., Beleboni, R.O., 2013. In vitro anthelmintic activity of aqueous leaf extract of Annona muricata L. (Annonaceae) against Haemonchus contortus from sheep. Exp. Parasitol. 134, 327-332. https://doi.org/10.1016/j.exppara.2013. 03.032

Haque, M.A., Hollister, W.S., Willcox, A., Canning, E.U., 1993. The Antimicrosporidial Activity of Albendazole. J. Invertebr. Pathol. 62, 171-177. https://doi.org/https://doi. org/10.1006/jipa.1993.1092

Jeyadevi, R.A., Sivasudha, T., Rameshkumar, A., Sangeetha, B., Ananth, D.A., Aseervatham, $\quad$ G.S.B., 2012. Nutritional constituents and medicinal values of Momordica cymbalaria (Athalakkai) - A review. Asian Pac. J. Trop. Biomed. 2, S456-S461. https://doi.org/https://doi.org/10.1016/ S2221-1691(12)60206-8

Kumarasingha, R., Preston, S., Yeo, T.C., Lim, D.S.L., Tu, C.L., Palombo, E.A., Shaw, J.M., Gasser, R.B., Boag, P.R., 2016. Anthelmintic activity of selected ethno-medicinal plant extracts on parasitic stages of Haemonchus contortus. Parasites and Vectors 9, 17. https://doi.org/10.1186/s13071-016- 
1458-9

Lemmich, E., Cornett, C., Furu, P., Jørstian, C.L., Knudsen, A.D., Olsen, C.E., Salih, A., Thiilborg, S.T., 1995. Molluscicidal saponins from Catunaregam nilotica. Phytochemistry 39, 63-68. https://doi.org/https://doi. org/10.1016/0031-9422(94)00866-R

Murugamani, V., Raju, L., Anand Raj, V.B., Sarma kataki, M., Sankar, G.G., 2012. The New Method Developed for Evaluation of Anthelmintic Activity by Housefly Worms and Compared with Conventional Earthworm Method. ISRN Pharmacol. 2012, 1-6. https://doi.org/10.5402/2012/709860

Nayak, S., Chakraborti, C.K., Jaiswal, P., Sah, U.K., Mohanta, D.S. Das, 2012. Correlation between the phytochemical constituents and anthelmintic activity of Lawsonia inermis leaf extracts. Int. J. Res. Ayurveda Pharm. 3, 559-562.

Oliveira, A.F., Costa Junior, L.M., Lima, A.S., Silva, C.R., Ribeiro, M.N.S., Mesquista, J.W.C., Rocha, C.Q., Tangerina, M.M.P., Vilegas, W., 2017. Anthelmintic activity of plant extracts from Brazilian savanna. Vet. Parasitol. 236, 121-127. https://doi.org/https:// doi.org/10.1016/j.vetpar.2017.02.005

Omobhude, M.E., Morenikeji, O.A.,
Oyeyemi, O.T., 2017. Molluscicidal activities of curcumin-nisin polylactic acid nanoparticle on Biomphalaria pfeifferi. PLoS Negl. Trop. Dis. 11, 112. https://doi.org/10.1371/journal. pntd.0005855

Pusuloori, R., Radhika, P., Vangoori, Y., 2017. Evaluation of Effect of Momordica Dioica Extract on Reproductive System of Male and Female Rats 10, 1419-1425.

Rabiu, H., Subhasish, M., 2011. Investigation of in Vitro Anthelmintic activity of Azadirachta Indica Leaves. Int. J. Drug Dev. Res. 3, 94-100.

Rajeswari, V., 2014. Anthelmintic activity of plants: A review. Res. J. Phytochem. 8, 57-63.

Talukdar, S.N., Hossain, M.N., 2014. Study of Momordica dioica. Biomed Res. Int. 2017.

Williams, A.R., Ropiak, H.M., Fryganas, C., Desrues, O., Mueller-Harvey, I., Thamsborg, S.M., 2014. Assessment of the anthelmintic activity of medicinal plant extracts and purified condensed tannins against free-living and parasitic stages of Oesophagostomum dentatum. Parasites and Vectors 7, 1-12. https:// doi.org/10.1186/s13071-014-0518-2.

\section{How to cite this article:}

Freny Jacob. 2018. Anti Helminthis and Molluscicidal Activity of Momordica dioica Against Pheretima posthumous and Indoplanorbis exustus. Int.J.Curr.Microbiol.App.Sci. 7(07): 39693974. doi: https://doi.org/10.20546/ijcmas.2018.707.462 